\title{
Changes in Brain Blood Flow on Frontal Cortex Depending on Facial Vibrotactile Stimuli
}

\author{
Hisao Hiraba1, Takako Sato ${ }^{2}$, Satoshi Nishimura², Masaru Yamaoka ${ }^{3}$, \\ Motoharu Inoue ${ }^{1}$, Mitsuyasu Sato ${ }^{1}$, Takatoshi Iida1, Satoko Wada1, \\ Tadao Fujiwara ${ }^{3}$ and Koichiro Ueda ${ }^{1}$ \\ ${ }^{1}$ Departments of Dysphasia Rehabilitation \\ ${ }^{2}$ Oral and Maxillofacial Surgery and \\ ${ }^{3}$ Physics, Nihon University, School of Dentistry \\ Japan
}

\section{Introduction}

We provide patients who have problems with reduced salivation (hyposalivation) with artificial saliva treatment, humectants, and salivary gland massage (Ueda et al. 2005). However, treatment with artificial saliva and humectants is symptomatic, and although salivary gland massage can reinvigorate weak glands, to do so is difficult for people with disabilities and has varying effects, depending on operator skill. Thus, we have focused on increasing salivation through the use of vibrotactile stimulation, as reported by Hiraba et al. (2008). Before using this apparatus on patients, it was necessary to first estimate the effect on normal subjects.

The biggest challenge with continuous use of stimulation is an adaptive effect. In particular, we were interested in determining whether the effect was continuous without attenuation, when patients continue using the apparatus every day (Despopoulos and Silbernagel, 2003). We investigated adaptation to the continuous use of vibrotactile stimuli for 4 or 5 days in the same subjects to determine whether this resulted in a decrease in salivation (Despopoulos and Silbernagel, 2003; Principles of Neural Science. 2000a). Before this experiment was performed, it was necessary to compare resting and stimulating salivary secretion and to investigate the most effective frequency for increasing salivary secretion. We examined the amount of salivation during vibrotactile stimuli with a single motor (1.9 $\mu \mathrm{m}$ amplitude) on the bilateral masseter muscle belly (on the parotid glands), using a dental cotton roll positioned at the opening of the secretory duct for $3 \mathrm{~min}$. Furthermore, we examined the amount of salivation during vibrotactile stimuli with single and double motors $(1.9 \mu \mathrm{m}$ and $3.5 \mu \mathrm{m}$ amplitudes) on the bilateral submandibular angles (on the submandibular glands). Then, we compared resting and stimulating salivation and investigated the most effective frequency for increasing salivary secretion. The effect of increased salivation in normal subjects was determined as the difference between resting and stimulating salivation.

We defined a 5-min interval as the recovery time between resting and stimulating salivation from a preliminary study. First, we examined the most effective frequency for salivation of 
the parotid glands among 89,114 , and $180 \mathrm{~Hz}$ with a single motor, and then we found the most effective frequency for salivation of the submandibular glands between 89 and $114 \mathrm{~Hz}$ with single and double motors. We discuss the effects of vibrotactile stimulation based on these results.

Furthermore, to study the mechanism of increased salivation evoked by vibrotactile stimuli, we recorded changes in brain blood flow $(\mathrm{BBF})$ at the frontal cortex and the pulse frequency during stimulation. When subjects listen to classical music (particularly Mozart), they develop a relaxed feeling. Specifically, the feeling of relaxation is produced by decreasing BBF in the frontal cortex. In particular, we suggest that the relaxed feeling is produced by an increase in parasympathetic activity. Furthermore, we examined changes in the pulse frequency during vibrotactile stimulation. A decrease in pulse frequency suggests an increase in parasympathetic activity (Principles of Neural Science. 2000b). Thus, we assumed a mechanism of increased salivation by exploring oxyhemoglobin (oxyHb) concentration in the $\mathrm{BBF}$ of the frontal cortex and changes in pulse frequency. We believe that the coordination is carried out by a highly interconnected set of structures in the brain stem and forebrain that form a central autonomic network (Principles of Neural Science. 2000b).

\section{Material and methods}

\subsection{Vibrotactile stimulation apparatus}

The vibrotactile stimulation apparatus consists of an oscillating body and control unit, as shown in Hiraba et al. (2008) and Yamaoka et al. (2007). The oscillating body is composed of the headphone headset equipped with vibrators as a substitute for positions of the bilateral microphones, and vibrators utilizing the vibration electric motor (VEM) (Rekishin Japan Co., LE12AOG). The VEM was covered in silicon rubber (polyethyl methacrylate, dental mucosa protective material, Shyofu Co.) for conglobating the stimulation parts and preventing the warming of the VEM's temperature produced by the vibration of long periods (Hiraba et al. 2008). The control unit consists of three parts, the pulse width modulation (PWM) circuit in Figure 1A-a, LCD monitor circuit (Figure 1A-b) and power supply circuit (Figure 1A-c), and it interfaced with a PWN electric motor, delivered vibration frequencies in the $60-182 \mathrm{~Hz}$ range (Yamaoka et al. 2007).

We examined the amount of salivation during vibrotactile stimuli on the bilateral masseter muscle belly (on the parotid glands) and on bilateral parts of the submandibular angle (on the submandibular glands; Fig. 1B, 1C). We determined the amount of salivation using a dental cotton roll ( $1 \mathrm{~cm}$ across, $3 \mathrm{~cm}$ length) positioned at the opening of the secretory ducts (right and left sides of the parotid glands and right and left sides of the submandibular and sublingual glands), during vibrotactile stimulation of the bilateral parotid and submandibular glands. The weights of the wet cotton rolls after 3 min of use were compared with their dry weights (Hiraba et al. 2008).

\subsection{Stimulating salivation in normal subjects}

We determined that a 3-min salivation measurement with a 5-min recovery time was sufficient from a previous experiment (Hiraba et al. 2008). First, we used three frequencies with a single motor $(89,114,180 \mathrm{~Hz}-\mathrm{S})$ on the parotid glands (Fig. 1B, 1D) and conducted a practice exercise so that the participants could learn to avoid the foreign-body sensation of the cotton rolls for $3 \mathrm{~min}$. Next, after a 5-min rest, we examined the amount of salivation during $89 \mathrm{~Hz}-\mathrm{S}$ vibrotactile stimulation for $3 \mathrm{~min}$. After every $5 \mathrm{~min}$ of rest, we examined the 
amount of salivation during 114 and $180 \mathrm{~Hz}-\mathrm{S}$ vibrotactile stimulation for $3 \mathrm{~min}$, respectively. We finally examined the amount of salivation on resting stimulation for $3 \mathrm{~min}$ (Fig. 1D). We conducted these tests with 19 normal subjects (6 males, 13 females; average age, 22 years). This experiment was performed between 3 and $5 \mathrm{pm}$ in a temperaturecontrolled, quiet room.
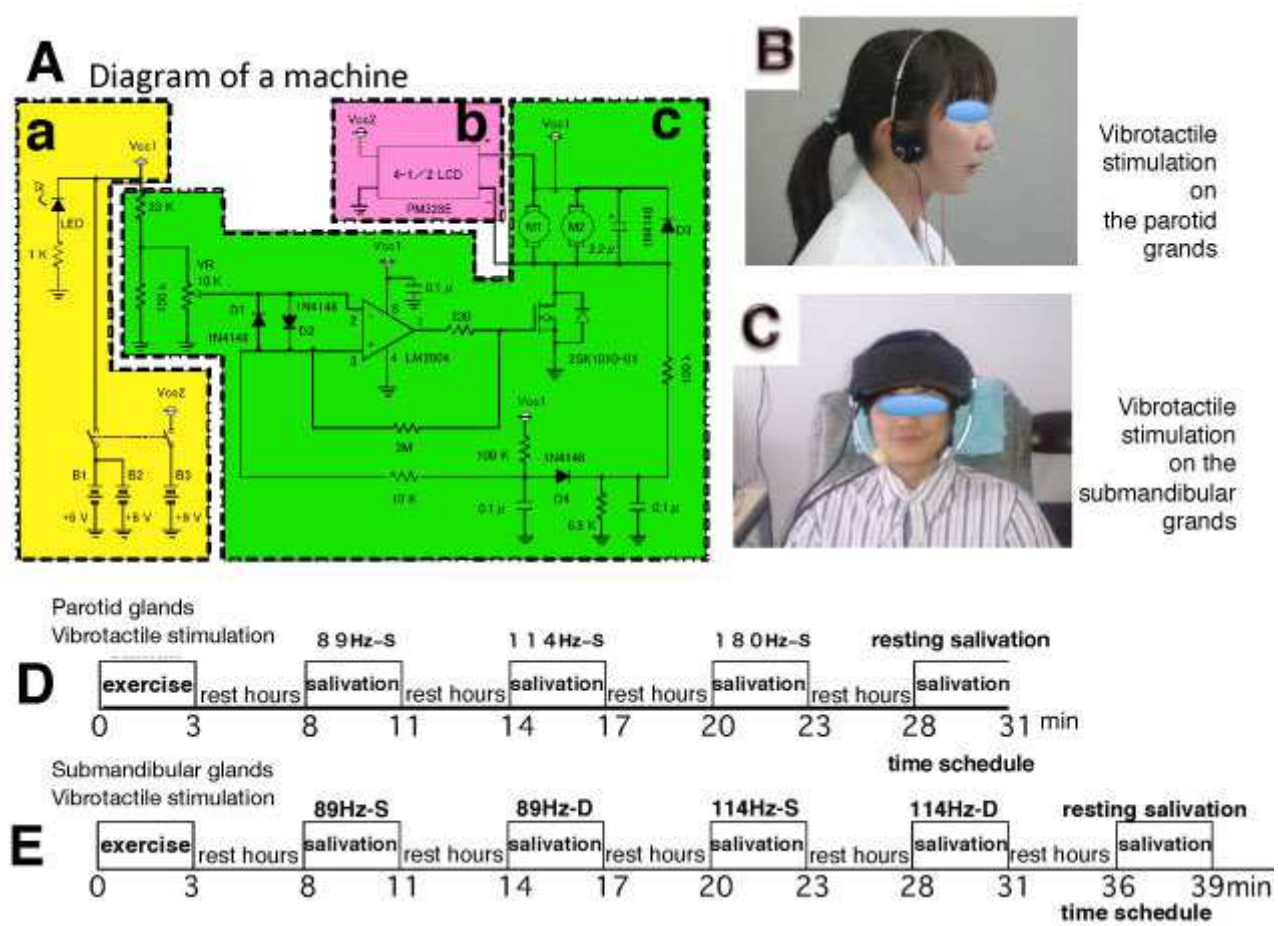

Fig. 1. Pictures and diagrams of the vibratory machine (A), experimental techniques (B and $\mathrm{C}$ ) and experimental schedules (D and E). B and C. Measuring salivation amount during vibrotactile stimulation of the bilateral masseter muscle belly (on the parotid glands, B) and the bilateral angle of the mandibular body (on the submandibular glands, C), using dental cotton rolls positioned at the opening of the secretory ducts (right and left sides of parotid glands and right and left sides of submandibular and sublingual glands). D and E. Time schedules for the vibrotactile stimuli, respectively. The designations $89 \mathrm{~Hz}-\mathrm{S}, 114 \mathrm{~Hz}-\mathrm{S}$ and $180 \mathrm{~Hz}-\mathrm{S}$ indicate vibrotactile stimuli at 89,114 , and $180 \mathrm{~Hz}$, respectively, with a single motor. The designations $89 \mathrm{~Hz}-\mathrm{D}$ and $114 \mathrm{~Hz}-\mathrm{D}$ represent vibrotactile stimuli of 89 and 114 $\mathrm{Hz}$ with double motors. We allowed a 5-min recovery time shown as "rest hours." Variation per day in the effective salivation during 4 or 5 days of continuous use at $89 \mathrm{~Hz}-\mathrm{S}$ vibrotactile stimulation for the right and left parotid glands, and the time schedule as shown in Figure 1D was repeated by subjects for 4 or 5 days.

After the three frequencies were tested on the parotid glands, we determined the most effective frequencies, which were 89 and $114 \mathrm{~Hz}-\mathrm{S}$. Second, we subjected the submandibular glands to the two frequencies $(89$ and $114 \mathrm{~Hz}$ ) and two different amplitudes (Fig. 1C, 1E). 
The amplitude of the oscillating bodies during vibrotactile stimulation was measured with a CCD laser displacement gauge (LK-G3000, Keyence Co., Osaka, Japan). We examined the 89 and $114 \mathrm{~Hz}$ frequencies and used oscillating bodies added as the frequency with double motors (single motor had a $1.9 \mu \mathrm{m}$ amplitude, 89 and $114 \mathrm{~Hz}-\mathrm{S}$, and double motors had a 3.5 $\mu \mathrm{m}$ amplitude, 89 and $114 \mathrm{~Hz}-\mathrm{D})$. Specifically, 89 and $114 \mathrm{~Hz}-\mathrm{S}$, and 89 and $114 \mathrm{~Hz}-\mathrm{D}$ were used in the next experiment. We examined the amount of salivation for the four frequencies (Fig. 1E). We conducted these experiments with 17 normal subjects (15 males, 2 females; average age, 22 years) for the resting-stimulation examination. This experiment was performed between 3 and 5 pm in a temperature-controlled, quiet room.

The most effective salivation amount by vibrotactile stimulating the parotid glands occurred at $89 \mathrm{~Hz}-\mathrm{S}$, so we examined changes in salivation for 4 or 5 continuous days with the same time schedule (Fig. 1D). We also investigated the adaptation periods during continuous use of vibrotactile stimulation for 4 or 5 continuous days in the same subjects. We conducted resting-stimulation examinations with 26 normal subjects (11 males and 15 females; average age 25 years). This experiment was performed between 3 and $5 \mathrm{pm}$ in a temperaturecontrolled and quiet room.

\subsection{BBF on the frontal cortex}

The recording was conducted using a functional near-infrared spectroscopy (fNIRS) OEG16 instrument (Spectratech Inc., Shelton, CT, USA) from the frontal cortex. As shown in Figures $4 \mathrm{~A}$ and $4 \mathrm{~B}$, the fNIRS probe assembly consisted of six LEDs as light sources, each of which emitted two wavelengths, $770 \mathrm{~nm}$ and $840 \mathrm{~nm}$, and six photodiodes as detectors (Fig. 4A, $4 \mathrm{~B})$. The sources and detectors were symmetrically arranged in an area of $3.0 \times 14.0 \mathrm{~cm}$, with a nearest source-detector separation of $2.0 \mathrm{~cm}$, and measurement points were at 16 points on the frontal cortex. During scanning, a Velcro band held the probe assembly securely to the forehead of subjects and extended from ear to ear horizontally and from hairline to eyebrows vertically. Each of the LEDs was turned on in sequence, and the diffuse NIR light from each source was acquired through the cortical region at the nearest detector. Thus, 16 source-detector pairs (channels) in total were measured (Fig. 4B). The sampling rate across all 16 channels was $0.76 \mathrm{~Hz}$. In particular, we showed a 16-channel computerized analysis (as shown in Fig. 4B) and the original waves of four channel recording areas in the central parts (original waves in Fig. 4C recorded over the selected areas in Fig. 4A).

We recorded BBF during vibrotactile stimulation. We also conducted a BBF experimental recording as subjects listened to classical music (Mozart, Eine kleine Nachtmusik). We conducted the examinations with 10 normal subjects ( 6 males, 4 females; average age, 22 years) for the resting-stimulation and classical music examinations. This experiment was performed between 3 and 5 pm in a temperature-controlled, quiet room.

\subsection{Pulse frequency during vibrotactile stimulation}

We recorded changes in pulse frequency (P225F, Nihon-Kohden Co., Tokyo, Japan) during vibrotactile stimuli at 89 and $114 \mathrm{~Hz}-\mathrm{S}$. Because the hemoglobin in blood absorbs red light irradiation, a pulse wave was calculated using a ratio between red light irradiation $(660 \mu \mathrm{m})$ and infrared light $(940 \mu \mathrm{m})$. The pulse frequency indicated by this apparatus was measured by averaging the pulse frequency during the previous eight pulses (Fig. 5C). First, the pulse frequency during rest was recorded for $1 \mathrm{~min}$, and then those during 89 and $114 \mathrm{~Hz}-\mathrm{S}$ vibrotactile stimuli were recorded for $2 \mathrm{~min}$ each. A 1-min rest period was taken between 
the 89 and $114 \mathrm{~Hz}-\mathrm{S}$ vibrotactile stimuli. Finally, the pulse frequency during rest was recorded for $30 \mathrm{~s}$. We conducted these examinations with 10 normal subjects $(6$ males, 4 females; average age, 22 years). This experiment was performed every day between 3 and 5 $\mathrm{pm}$ in a temperature-controlled, quiet room.

\section{Results}

\subsection{Vibrotactile stimuli on the parotid and submandibular glands}

We examined the differences between vibrotactile stimulating of parotid and submandibular glands (Fig. 1B, 1C). First, we tested three frequencies of vibrotactile stimulation, 89,114 , and $180 \mathrm{~Hz}-\mathrm{S}$, on the parotid glands and determined the frequency most effective for salivation (Fig. 2A). We found that the most effective frequencies for submandibular gland salivation were $89 \mathrm{~Hz}-\mathrm{S}, 89 \mathrm{~Hz}-\mathrm{D}, 114 \mathrm{~Hz}-\mathrm{S}$, and $114 \mathrm{~Hz}-\mathrm{D}$ (Fig. 2B) and that the erase most effective stimulation was $89 \mathrm{~Hz}-\mathrm{S}$ (Fig. 2A, 2B; p < 0.05).

We examined the most effective salivation in each gland, including the right parotid, left parotid, right submandibular and sublingual and left submandibular and sublingual glands. As a result, the most effective stimulation for salivation of the parotid and submandibular glands was $89 \mathrm{~Hz}-\mathrm{S}$ (Fig. 2A-a, 2B-a; resting salivation, $0.89 \pm 0.61 \mathrm{~mL} ; 89 \mathrm{~Hz}-\mathrm{S}, 1.46 \pm 0.90 \mathrm{~mL}$; $89 \mathrm{~Hz}-\mathrm{D}, 1.04 \pm 0.78 \mathrm{~mL} ; 114 \mathrm{~Hz}-\mathrm{S}, 0.93 \pm 0.76 \mathrm{~mL}$ and $114 \mathrm{~Hz}-\mathrm{D}, 0.80 \pm 0.53 \mathrm{~mL}$ ). Furthermore, a significant difference was observed between the vibrotactile stimulation at $89 \mathrm{~Hz}-\mathrm{S}$ and that at $114 \mathrm{~Hz}-\mathrm{D}$ (paired $t$-test; $\mathrm{p}<0.05$ ). No other significant difference in each gland was observed (Fig. 2A-b, 2A-c, 2B-b, 2B-c, 2B-d and 2B-e).
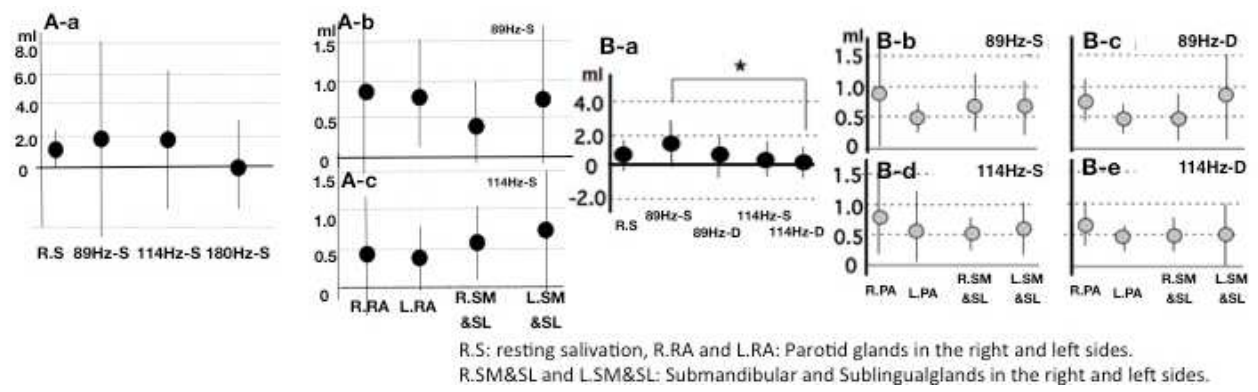

Fig. 2. Salivation from the parotid glands (A) and the submandibular glands (B) after each vibrotactile stimulation. $\mathbf{A}-\mathbf{a}$ and $\mathbf{B}-\mathbf{a}$. Total number of salivations after each vibrotactile stimulation. A-b, A-c, B-b, B-c, B-d and B-e. Salivation amount for each gland after various vibrotactile stimuli. The increased salivation between $89 \mathrm{~Hz}-\mathrm{S}$ and $114 \mathrm{~Hz}-\mathrm{D}$ was significantly different (paired-t-test; $\mathrm{p}<0.05$ ). Stimulating the parotid or submandibular glands at $89 \mathrm{~Hz}-\mathrm{S}$ was the most effective for salivation. Salivation was not different among the various glands (parotid and submandibular and sublingual glands on the right and left sides).

3.2 Variation in effective salivation per day during continuous vibrotactile stimulation Because patients with hyposalivation often have a psychiatric disorder, we conducted an experiment to realistically approximate natural conditions. We examined whether effective salivation occurred continuously when vibrotactile stimulation was performed daily. In 
particular, we used the $89 \mathrm{~Hz}-\mathrm{S}$ from the previous experiment, and because no difference was found between vibrotactile stimulation of the parotid and submandibular glands, we analyzed salivation evoked by vibrotactile stimulation of the parotid glands. Normal subjects (15 males, 11 females; average age, 25 years) used this apparatus continuously for 4 or 5 days at the same time and place (Fig. 3). None of the glands (right and left parotid glands, and right submandibular and sublingual glands) showed an attenuated response. Regression curves for each gland (Fig. 3A, 3B, 3C and 3D) showed non-adaptation to continuous stimulation, because they showed parallel or over-increasing curves, indicating that continuous usage of this apparatus should not be a problem.
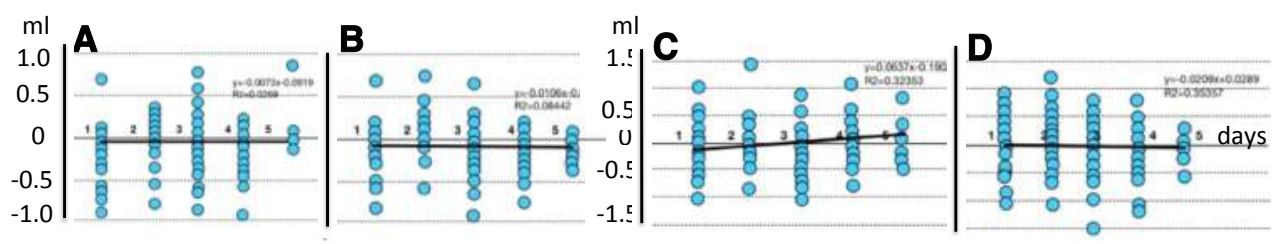

Fig. 3. Variation in effective salivation per day during 4 or 5 days of continuous use of 89 $\mathrm{Hz}-\mathrm{S}$ vibrotactile stimulation in the right $(\mathrm{A})$ and left parotid (B) and the right (C) and left submandibular and sublingual glands (D). The time schedule, as shown in Figure 1D, was repeated by subjects for 4 or 5 days. Vertical lines indicate the increase and decrease in vibrotactile salivation versus resting salivation (it is shown by a positive value when the vibrotactile salivation was greater than the resting salivation, and by a negative value when the vibrotactile salivation was lower than the resting salivation). Abscissa lines indicate time (4-5 days). Solid lines indicate the regression curve. There was no adaptation to the $89 \mathrm{~Hz}-\mathrm{S}$ vibrotactile stimulation in the parotid, submandibular, or sublingual glands.

\subsection{Relationship between each stimulation and fNIRS activity}

The OEG16 spectroscope was used to record the hemoglobin concentration in the BBF from areas in the frontal cortex using 16 channels. In particular, we measured original waves in four channel recording areas (circled 1, 2, 3, and 4 in Fig. 4A). Figure 4B shows the schema of the oxyhemoglobin (oxyHb) concentration evoked by analyzing 16 channels during vibrotactile stimulation at $89 \mathrm{~Hz}-\mathrm{S}$. The contrasting red and blue zones indicate activity strength, and no response is shown in white (Fig. 4B). The results showed very weak oxyHb concentrations during the $89 \mathrm{~Hz}-\mathrm{S}$ vibrotactile stimulation, as shown in Figure 4C-b.

We provided evidence of the real waves on the central parts (circled 1, 2, 3, 4; Fig. 4A) of the $\mathrm{BBF}$ recording in 16 channels (Fig. 4C). The red lines indicate changes in oxyHb concentrations, the blue lines indicate deoxyhemoglobin (deoxyHb), and the green lines indicate total hemoglobin (total $\mathrm{Hb}$ ) during salivation measurements at rest and for each vibrotactile stimulation frequency. The first waves in Figure $4 \mathrm{C}(\mathrm{a})$ indicate changes during the resting condition, the second waves (b) show changes during $89 \mathrm{~Hz}-\mathrm{S}$ vibrotactile stimulation, the third waves (c) show changes during $89 \mathrm{~Hz}-\mathrm{D}$, the fourth waves (d) show changes during $114 \mathrm{~Hz}-\mathrm{S}$, the fifth waves (e) show changes during $114 \mathrm{~Hz}-\mathrm{D}$ and the bottom waves (f) show changes during "A-" phonation. Each wave was recorded for $3 \mathrm{~min}$, and each vibrotactile stimulation provided for $2 \mathrm{~min}$ is shown between the vertical lines. However, "A-“ phonation is shown by four applicable vertical lines. Although each wave 


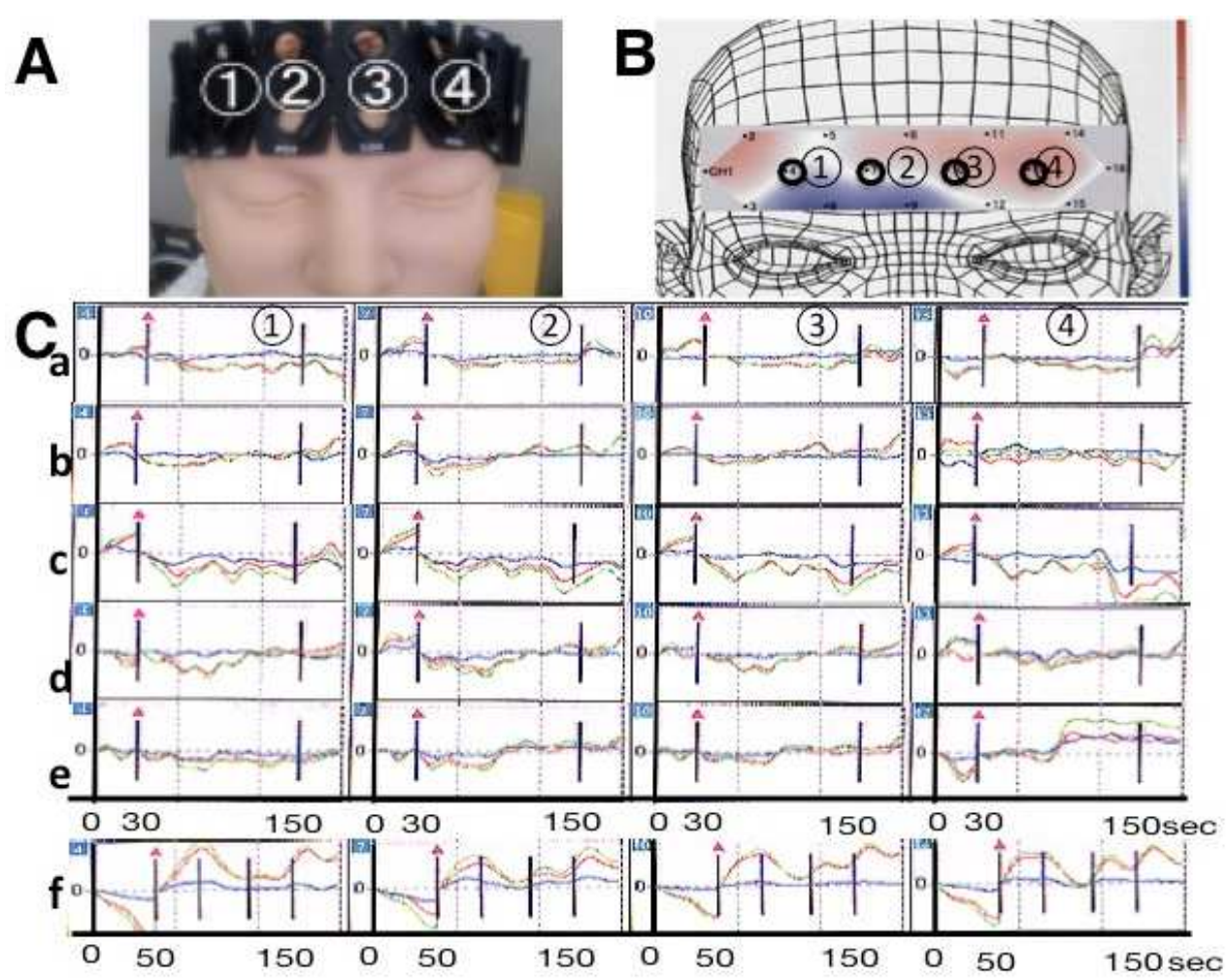

Fig. 4. A. Frontal cortex recording sites. The circled numbers 1, 2, 3, and 4 indicate the recording sites for each wave, as shown in C. B. A computerized numerical analysis of variations in oxyhemoglobin (oxyHb) concentration during $89 \mathrm{~Hz}-\mathrm{S}$ vibrotactile stimulation. Red (plus) and blue shading (minus) indicates differences in frontal cortex activation, whereas the white band indicates non-activation. C. Changes in blood brain flow during 2 min of various vibrotactile stimuli and vocalizing "A-" sounds are shown at the central areas of the frontal cortex. C-a. During the resting condition. C-b. During $89 \mathrm{~Hz}-\mathrm{S}$ vibrotactile stimulation. C-c. During 89 Hz-D vibrotactile stimulation. C-d. During $114 \mathrm{~Hz}-\mathrm{S}$ vibrotactile stimulation. C-e. During $89 \mathrm{~Hz}-\mathrm{D}$ vibrotactile stimulation. C-f. While vocalizing "A-" sounds. The spaces between the solid bars (2 min.) represents the stimulating period. However, vertical lines during vocalizing "A-“ sounds were the timely accomplishment between good winds. Red, blue, and green lines indicate oxyhemoglobin, deoxyhemoglobin, and total hemoglobin concentrations, respectively. 
measured during resting salivation, at $114 \mathrm{~Hz}-\mathrm{D}$, and during "A-" phonation showed increased activity, the $89 \mathrm{~Hz}-\mathrm{D}$ and $114 \mathrm{~Hz}-\mathrm{S}$ vibrotactile stimuli showed decreased activities. However, vibrotactile stimulation at $89 \mathrm{~Hz}-\mathrm{S}$ was fairly close to zero value $(0.14 \pm 1.10 \mathrm{mM} \mathrm{mm} \cdot \mathrm{s})$. In particular, when we focused on changes in oxyHb based on these results, increased oxyHb occurred during "A-" phonation, the resting condition $(5.20 \pm 6.78$ $\mathrm{mM} \mathrm{mm} \cdot \mathrm{s})$ and at $114 \mathrm{~Hz}-\mathrm{D}$ of vibrotactile stimulation $(-0.13 \pm 3.54 \mathrm{mM} \mathrm{mm} \cdot \mathrm{s})$, whereas a decrease in oxyHb was revealed during vibrotactile stimulation at $114 \mathrm{~Hz}-\mathrm{S}(-5.48 \pm 7.12 \mathrm{mM}$ $\mathrm{mm} \cdot \mathrm{s})$ and at $89 \mathrm{~Hz}-\mathrm{D}(-2.18 \pm 10.13 \mathrm{mM} \mathrm{mm} \cdot \mathrm{s})$. However, oxyHb during vibrotactile stimulation at $89 \mathrm{~Hz}-\mathrm{D}(0.29 \pm 2.26 \mathrm{mM} \mathrm{mm} \cdot \mathrm{s})$ was near zero, similar to all of the data (oxyHb, deoxyHb, total $\mathrm{Hb}$ ). From these results, we computed integral rates of oxyHb during $2 \mathrm{~min}$, as shown by the area between the longitudinal bars in the central part (circled 1, 2,3, and 4) of the recording wave (Fig. 4C).

Furthermore, we examined the integral rates while subjects listened to classical music for 2 min. We divided the subjects into two groups: one group did not like to listen to classical music $(2.96 \pm 6.40 \mathrm{mM} \mathrm{mm} \cdot \mathrm{s}, n=7)$ whereas the other group did $(0.85 \pm 0.05 \mathrm{mM} \mathrm{mm} \cdot \mathrm{s}, n=3$; Fig. $5 \mathrm{~A}$ and $5 \mathrm{~B}$, respectively). Although the subjects who enjoyed the music did not show a larger spread of values $( \pm S D)$, the latter did. In particular, vibrotactile stimulation at $89 \mathrm{~Hz}-\mathrm{S}$ revealed a small similar spread of values. Each integral rate during the vibrotactile stimulation at $89 \mathrm{~Hz}-\mathrm{S}$ and while the listening to classical music showed similar averages and SDs (Fig. 5B-b).

\subsection{Pulse frequency during vibrotactile stimulation and frontal cortex fNRS activity}

We chose three typically responding subjects, as shown in Figure 5C. One subject showed a decrease in pulse frequency during both $89 \mathrm{~Hz}-\mathrm{S}$ and $114 \mathrm{~Hz}-\mathrm{S}$ vibrotactile stimulation, while the other two showed a decrease in pulse frequency at $89 \mathrm{~Hz}-\mathrm{S}$ and an increase during $114 \mathrm{~Hz}-\mathrm{S}$ stimulation (Fig. 5C). We divided the two groups into decrease pulse frequency and increase pulse frequency groups, based on $114 \mathrm{~Hz}-\mathrm{S}$ vibrotactile stimulation. Although the $89 \mathrm{~Hz}-\mathrm{S}$ vibrotactile stimulation created a sense of relaxation, the $114 \mathrm{~Hz}-\mathrm{S}$ vibrotactile stimulation is either liked or disliked. Specifically, the $89 \mathrm{~Hz}-\mathrm{S}$ vibrotactile stimulation will produce parasympathetic activity and evoke a relaxation response.

\section{Discussion}

\subsection{Adaptation to vibrotactile stimulation}

Continuous exposure to various sensory stimuli induces adaptation (Principles of Neural Science. 2000c). Thus, we examined whether adaptation occurred to the vibrotactile stimulation when normal subjects continuously used this apparatus every day for 4 or 5 days. However, we first investigated changes in total saliva secretion quantities by normal subjects in response vibrotactile stimulation by measuring the weights of cotton rolls set on the ducts of each gland. For the repeated measurements, we defined a recovery time of 5 min from a previous experiment, as resting salivation values before and after stimulating salivation were the same (Fig. 1D, 1E).

The most effective frequency for increasing the total amount of salivation during vibrotactile stimulation of the parotid and submandibular glands was $89 \mathrm{~Hz}-\mathrm{S}$ (Fig. 2A-a, 2B-a). Furthermore, as shown in Figures $2 \mathrm{~A}-\mathrm{b}$ and $2 \mathrm{~A}-\mathrm{c}$, and 2B-b, 2B-c, 2B-d and 2B-e, no difference was found among the various glands. Because $89 \mathrm{~Hz}-\mathrm{S}$ vibrotactile stimulation of the parotid and submandibular glands showed the same results in all glands, the results 
might not be directly affected by the vibrotactile stimulation on the parotid and submandibular glands. Specifically, the increased salivation evoked by vibrotactile stimulation at $89 \mathrm{~Hz}-\mathrm{S}$ may be the result of somatosensory input from the facial skin and intraoral cavity.

Burdette and Gale (1988) reported that tonic masticatory muscle activity may be effective for treating patients with myofacial pain dysfunction. Furthermore, Vrjama and Vanharantra (1994) reported that discographically painful discs always decrease pain during a vibration examination. These results assume that the peripheral stimuli provided by the vibration arrive at the central nervous system (spinal cord and brain stem) and that these effects are produced by a depressant effect on the cerebral cortex, depending on the somatosensory information, although they are not clearly organized. We believe that their interpretation does not adequately explain this situation. We suggest that vibrating stimuli may promote parasympathetic effects by inhibiting the sympathetic effects elicited by pain. We know serous salivation is evoked only by a parasympathetic effect. Furthermore, we found that salivation production responded to a specific frequency and amplitude.

Vibration may effectively activate the muscle spindles of the masseter muscles, because the tonic vibration reflex (TVR) of the muscle spindles activates with $80-100 \mathrm{~Hz}$ vibrations (Desmedt, Codaux 1975). However, we showed the same salivation response in various glands. We showed that increased salivation evoked by $89 \mathrm{~Hz}-\mathrm{S}$ vibrotactile stimulation would be produced by somatosensory inputs from facial skin and the intraoral cavity, suggesting that increased salivation is not produced by a direct effect of muscle contraction.

Next, we examined the physiological characteristics of adaptation to vibrotactile stimulation by testing adaptation in 26 normal subjects for 4 or 5 days. Patients with decreased salivation (hyposalivation) would be using this machine daily; thus, we wanted to realistically approximate actual conditions. The results suggested that $89 \mathrm{~Hz}-\mathrm{S}$ vibrotactile stimulation to the facial skin of the masseter belly may be appropriate for patients with decreased salivation, because the regression curve (negative gradient) did not decrease with continuous use of the apparatus (Fig. 3).

\section{2 fNIRS activity in the frontal cortex}

The frontal cortex is associated with cognitive function, including memory, attention, abstract reasoning and higher cognitive activity (Principles of Neural Science. 2000a).

We recorded changes in BBF in the frontal cortex to examine typical changes in fNIRS parameters based on increases in oxyHb and total $\mathrm{Hb}$ and decreased deoxy $\mathrm{Hb}$, as reported by Sakatani et al. (2006). In particular, increased fNIRS activity patterns in the frontal cortex are associated with speech, and decreased fNIRS activity patterns in the frontal cortex are associated with playing TV games and are thought to be dependent on network differences (Sakatani et al. 1999). The fNIRS responses may be influenced by mental stability, because they indicate control of sophisticated mental functions produced by complex networks. Because fNIRS activity increases while subjects are speaking and decreases while they play TV games, we suggest that the autonomic system has a profound effect. Specifically, we suggest that fNIRS activity during conscious speaking is associated with a sympathetic effect, and that playing a TV game is associated with reflective movement under a nonsympathetic effect.

The effect of $89 \mathrm{~Hz}-\mathrm{S}$ vibrotactile stimulation was almost zero for oxyHb, deoxyHb, and totalHb (Fig. 4C-b). In particular, the fNIRS activity focuses on the excitatory behaviours to 
increase oxyHb. In animal experiments, changes in oxyHb and BBF are related, and fNIRS activity changes in oxyHb are used as a neuronal activity index (Hoshi et al. 2001). Thus, changes in oxy Hb produced by an $89 \mathrm{~Hz}-\mathrm{S}$ vibrotactile stimulation on the parotid and submandibular glands may indicate mental stability. The reason may be due to the same tendency of oxyHb concentration between the $89 \mathrm{~Hz}-\mathrm{S}$ vibrotactile stimulation and subjects who liked to listen to classical music (Fig. 5B-b). People relax when they listen to classical music, so we think that $89 \mathrm{~Hz}-\mathrm{S}$ vibrotactile stimulation is produced by excitation of the parasympathetic system. In particular, although the $89 \mathrm{~Hz}-\mathrm{S}$ vibrotactile stimulation always
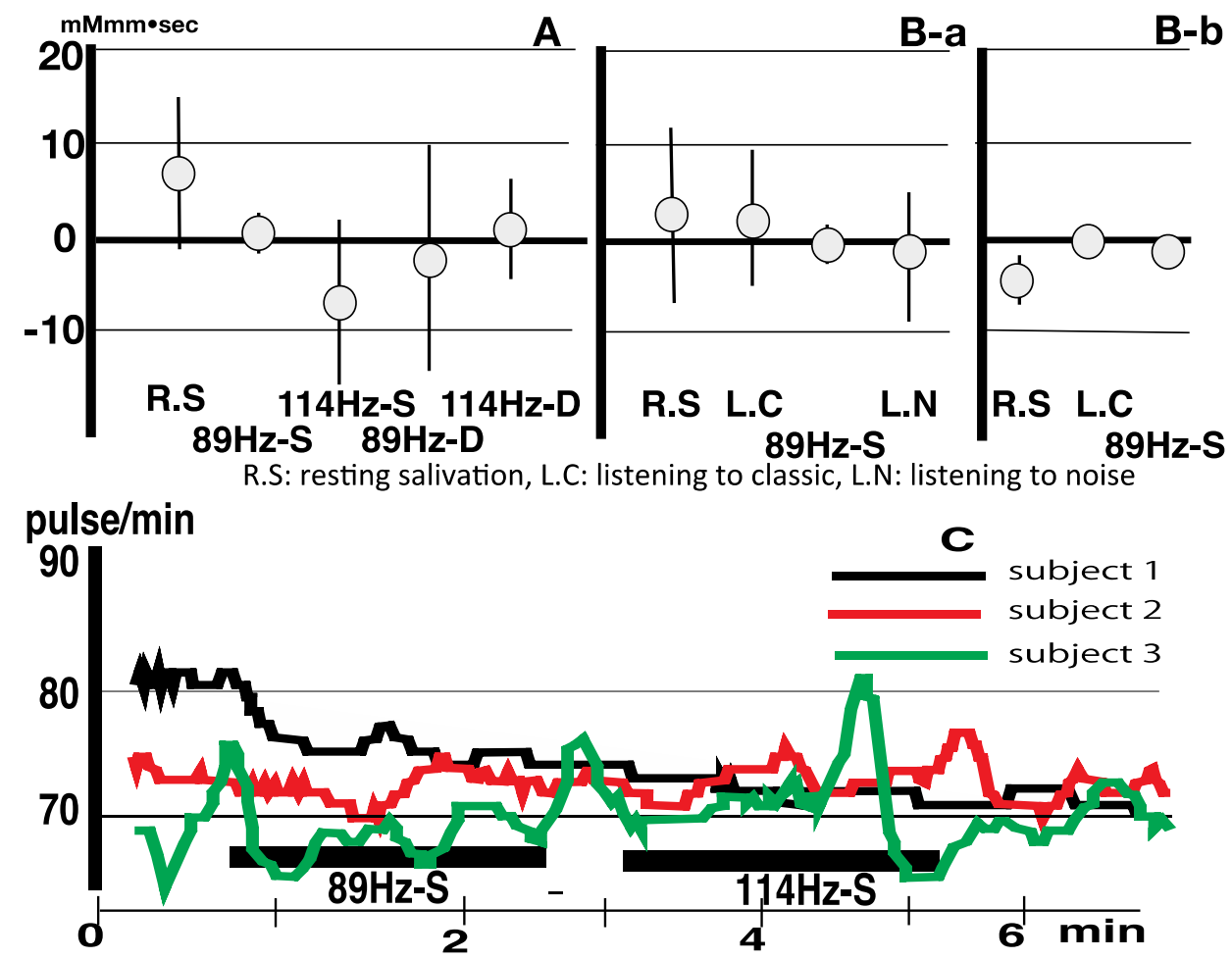

Fig. 5. Integral values of oxyhemoglobin $(\mathrm{oxyHb})$ concentration produced by vibrotactile stimuli for 2 min are shown in A and B. A. Integral values produced in the resting condition and after each stimulation $(n=17)$. B. Integral values produced in the resting condition, listening to classical music (Mozart, Eine kleine Nachtmusik), $89 \mathrm{~Hz}-\mathrm{S}$ and listening to noise $(n=10)$. One group enjoyed listening to classical music (D-b, $n=3)$, and one did not (D-a, $n$ = 7). C. Changes in pulse frequency during vibrotactile stimulation $(89 \mathrm{~Hz}-\mathrm{S}$ and $114 \mathrm{~Hz}-\mathrm{S})$. We assessed 10 normal subjects, and changes in pulse frequencies are shown for three typical subjects. All subjects had decreased pulse frequency during $89 \mathrm{~Hz}-\mathrm{S}$ vibrotactile stimulation, although the $114 \mathrm{~Hz}-\mathrm{S}$ vibrotactile stimulation divided the subjects into two groups: one showed an increased pulse frequency and the other showed a decreased pulse frequency. 
revealed parasympathetic excitation, listening to classical music showed different activity depending on music preference (Fig. 5B-a, 5B-b). Those subjects who enjoyed Mozart classical music accepted it as relaxing, whereas those who disliked it perceived it as noise. However, $89 \mathrm{~Hz}-\mathrm{S}$ vibrotactile stimulation may produce a balanced mental condition, regardless of preference. This phenomenon suggests that the effect caused by the $89 \mathrm{~Hz}-\mathrm{S}$ vibrotactile stimulation and the feeling sensed by those listening to Mozart who enjoyed it may be the same. Thus, we suggest that these feelings were produced by parasympathetic activity.

Burdette and Gale (1988) reported that tonic masticatory muscle activity might be effective for treating patients with myofascial pain-dysfunction. Furthermore, Vrjama and Vanharantra (1884) reported that discography always results in less pain during a vibration examination. They suggested that peripheral stimuli produced by the vibration arrive at the central nervous system (spinal cord and brain stem) and that these effects are caused by a depressant effect on the cerebral cortex, depending on the somatosensory information (Burdette and Gale, 1988; Vrjama and Vanharantra, 1884). However, we believe that somatosensory information via the thalamus produces excitability in the primary somatosensory cortex. Furthermore, somatosensory information in the primary somatosensory cortex may project to the frontal cortex via the parietal association area (Handbook of Neuropsychology 1994), and this information may cause the excitatory effects.

\subsection{Parasympathetic effect based on $89 \mathrm{~Hz}-\mathrm{S}$ vibrotactile stimulation}

When we are frightened, our heartbeat increases (Principles of Neural Science. 2000b). The parasympathetic nervous system is responsible for rest and digestion, and maintaining basal heart rate, respiration, and metabolism under normal, resting conditions (Principles of Neural Science. 2000b). We examined the parasympathetic effects with changes in pulse frequency during vibrotactile stimulation. We showed changes in pulse frequency in typical normal subjects in response to $89 \mathrm{~Hz}-\mathrm{S}$ and $114 \mathrm{~Hz}-\mathrm{S}$ vibrotactile stimuli (Fig. 5C). These results showed a decrease in pulse frequency during $89 \mathrm{~Hz}-\mathrm{S}$ stimulation, but an increase in pulse frequency following the $114 \mathrm{~Hz}-\mathrm{S}$ vibrotactile stimulation, except for one subject. Specifically, the $114 \mathrm{~Hz}-\mathrm{S}$ vibrotactile stimulation showed variable results, because one subject was relaxed, whereas the others were not. However, the $89 \mathrm{~Hz}-\mathrm{S}$ vibrotactile stimulation resulted in decreased pulse frequency in all subjects, suggesting that stimulating the face evoked parasympathetic stimulation (Fig. 5C). Thus, the parasympathetic activity elicited by $89 \mathrm{~Hz}-\mathrm{S}$ vibrotactile stimulation, may produce an increase in salivation. We reiterate that a relaxed feeling was produced in all subjects during $89 \mathrm{~Hz}-\mathrm{S}$ vibrotactile stimulation.

We consider the following schema for this phenomenon. Vibrotactile stimulation to the face produces somatosensory information activity in the orofacial region, which projects to the trigeminal sensory complex (principal trigeminal sensory nuclei and trigeminal spinal tract nuclei) and solitary nuclei (Fig. 6). This somatosensory information is divided into the parabrachial nuclei, thalamus, and hypothalamus. Information projecting to the parabrachial nuclei arrives in the hypothalamus, amygdala, and frontal cortex and then to the thalamus and primary somatosensory cortex (SI). Petrides reported that information travelling to the SI goes around the frontal cortex via the parietal association area (Handbook of Neuropsychology 1994). We think that somatosensory information travelling 
via the parietal association area represents excitability. If the BBF in the frontal cortex via the parietal association area is excitable and that via the parabrachial nucleus is inhibitory, which wave forms will be revealed? We believe that BBF to the frontal cortex evoked by various stimuli shows various wave forms, depending on the condition. In particular, the 89 $\mathrm{Hz}-\mathrm{S}$ vibrotactile stimulation may produce a relaxed feeling.

\subsection{Projection of autonomic activity in the frontal cortex}

Autonomic function must ultimately be coordinated by adapting to environmental changes. The autonomic nervous system is a visceral sensory and motor system, and the visceral reflex is mediated by local circuits in the brain stem or spinal cord. These reflexes are regulated by networks of central autonomic control nuclei in the brain stem, hypothalamus and forebrain and are not under voluntary control, nor do they impinge on consciousness, with a few exceptions (Principles of Neural Science. 2000b). However, we think that changes in BBF in the frontal cortex may represent autonomic activity. This coordination is carried out by a highly interconnected set of structures in the brain stem and forebrain that form a central autonomic network (Fig. 6 and Principles of Neural Science. 2000b). Furthermore, the key component of this network is initiated by integral information in the parabrachial nucleus of the solitary tract and trigeminal sensory complex in the brain stem. These nuclei receive inputs from somatosensory and visceral afferents of the trigeminal, facial, glossopharyngeal, and vagus nerves and then use the information to modulate autonomic function. The somatosensory and visceral sensory outputs from the trigeminal and solitary nuclei are relayed to the forebrain and amygdala by the parabrachial nucleus, which is important for the behavioural responses to somatosensory, taste, and other visceral sensations (Principles of Neural Science. 2000b), and the information arriving in the amygdala will produce the pleasure-pain feeling. In contrast, the parabrachial nucleus is a taste-sensation relay nucleus in rats (Scott and Small 2009), and the rodent parabrachial nucleus sends integral limbic and reward system information (Yamamoto et al. 2009). Although their function in humans is unknown, we think that these nuclei may play a role as a relay nucleus for the autonomic system. On the other hand, we showed a projection from the trigeminal sensory complex, as the parabrachial nucleus can also record the response to tactile stimuli from facial skin (Chiang et al, 1994). Furthermore, somatosensory information is projected to the primary somatosensory cortex and is then relayed to the frontal cortex, via the parietal association area (Handbook of Neuropsychology 1994).

What does BBF activity in the frontal cortex mean? We think that the information via the parabrachial nucleus dominates that via the parietal association area. Thus, information in the frontal cortex is assumed to arrive via the parabrachial nucleus area. The hypothalamus is the centre of the autonomic system. We perceive emotional experiences such as fear, pleasure, and contentment and these reflect the interplay between higher brain centres and sub-cortical regions, such as the hypothalamus and amygdala (Principles of Neural Science. 2000a). Patients in whom the prefrontal cortex or the cingulate gyrus has been removed are no longer bothered by pain, but exhibit appropriate autonomic reactions; however, the sensation is not perceived as a powerfully unpleasant experience (Principles of Neural Science. 2000a). Furthermore, the anatomical connections of the amygdala with the temporal (cingulate gyrus) and frontal (prefrontal) association cortices provide the means by which visceral and somatosensory sensations trigger a rich assortment of associations or the cognitive interpretation of emotional states (Principles of Neural Science. 2000b). 


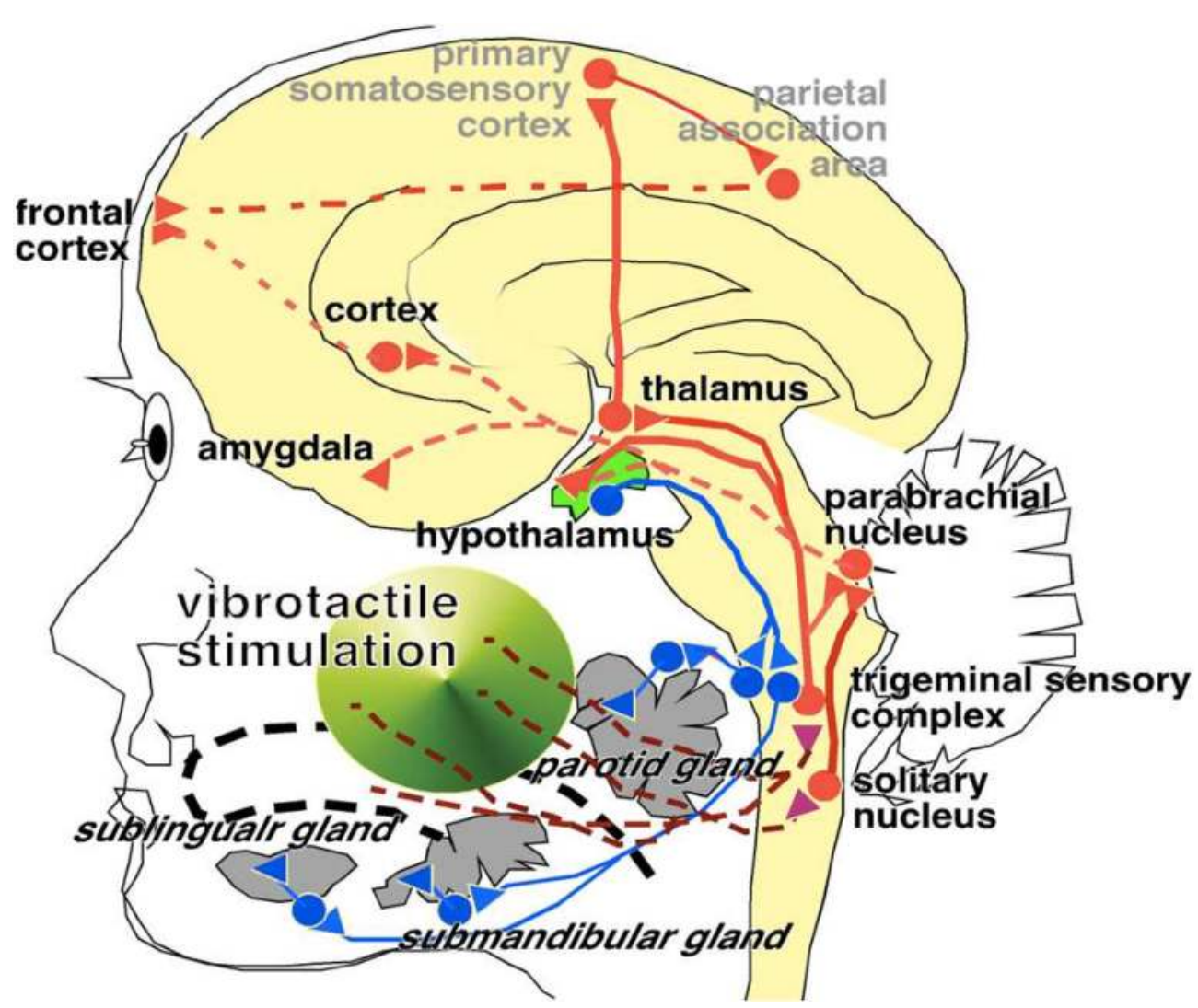

Fig. 6. Pathways distributing somatosensory information in the brain. Somatosensory information evoked by vibrotactile stimulation is relayed by the trigeminal sensory complex and solitary and parabrachial nuclei, which arrives at the hypothalamus, thalamus, amygdala and frontal cortex, respectively. The autonomic system (particularly the parasympathetic nervous system) produces increased salivation. The lateral branch of the trigeminal sensory nucleus is projected to the parabrachial nucleus. Information from the parabrachial nucleus is received by the amygdala and frontal cortex. Furthermore, somatosensory information is projected to the primary somatosensory cortex and relayed to the frontal cortex via the parietal association area. Thus, this information finally leads to a relaxed feeling and BBF waves reflect parasympathetic activity (modified from schemas in Principles of Neural Science 2000b and Handbook of Neuropsychology 1994). 
Finally, we showed oxyHb activity during "A-“ phonation (Fig. 4C-f). Sympathetic activity increases when we speak. From our data, the facial stimulation effects evoked by $89 \mathrm{~Hz}-\mathrm{S}$ vibrotactile stimulation evoked parasympathetic activity, depending on the decrease in pulse frequency, and oxyHb concentration reflected the non-activation of BBF waves in the frontal cortex. We suggest that the $89 \mathrm{~Hz}-\mathrm{S}$ vibrotactile stimulation produced a relaxing sensation depending on excitation in the amygdaloid complex and parasympathetic activity in the hypothalamic nuclei. The relaxing sensation was reflected by the oxyHb concentration of the BBF wave in the frontal cortex.

\section{Conclusion}

We showed that the most effective salivation response was produced by an $89 \mathrm{~Hz}$ vibrotactile stimulation with a single motor $(1.9 \mu \mathrm{m}$ amplitude) on the parotid glands, as reported previously (Hiraba et al. 2008). In this study, we focused on the submandibular glands secreting the greatest amount of saliva and explored changes in salivation during stimulation of the submandibular glands with $89 \mathrm{~Hz}$ and $114 \mathrm{~Hz}$ vibrotactile stimuli using single ( $89 \mathrm{~Hz}-\mathrm{S}$ and $114 \mathrm{~Hz}-\mathrm{S}$ ) or double motors ( $3.5 \mu \mathrm{m}$ amplitude, $89 \mathrm{~Hz}-\mathrm{D}$ and $114 \mathrm{~Hz}-\mathrm{D})$, respectively. The increased salivation evoked by the $89 \mathrm{~Hz}-\mathrm{S}$ vibrotactile stimulation was produced by somatosensory inputs from the facial skin and intraoral cavity. We examined the effects of vibrotactile stimulation on adaptation in normal subjects to test the effect of continuously using this apparatus every day by patients with hyposalivation. The results showed no adaptation with continuous use. Furthermore, we investigated changes in BBF in the frontal cortex during vibrotactile stimulation. Stimulating the submandibular and parotid glands at $89 \mathrm{~Hz}-\mathrm{S}$ resulted in the most salivation. OxyHb concentrations in the BBF to the frontal cortex during an $89 \mathrm{~Hz}$-S vibrotactile stimulation were the same as those in subjects who preferred listening to classical music. Furthermore, parasympathetic activity decreased pulse frequency during an $89 \mathrm{~Hz}-\mathrm{S}$ vibrotactile stimulation, suggesting a close relationship between the BBF waves in the frontal cortex and the autonomic system. An $89 \mathrm{~Hz}-\mathrm{S}$ vibrotactile stimulation may produce relaxation and salivation may be increased by parasympathetic excitation.

\section{Acknowledgements}

This work was supported by a Sogoshigaku research grant and the Sato Fund of Nihon University School of Dentistry, as well grants from the Ministry of Education and Grants-inAid for Scientific Research (21592539).

\section{References}

Ueda K. 2005. Sessyoku enge rehabilitation. In: Uematsu H, Inaba S, Watanabe M, editors. Koureishya Shika guidebook. Tokyo: Ishiyaku. pp 248-275 (in Japanese).

Hiraba H., M. Yamaoka, M. Fukano, K. Ueda and T. Fujiwara (2008) Increased secretion of salivary glands produced by facial vibrotactile stimulation. Somatosensory and Motor Research 25, 222-229. 
Despopoulos, A. and Silbernagl, S (2003) 10 Nutrition and digestion. In: Color Atlas of Physiology. $5^{\text {th }}$ ed. New York, Medical science international Ltd. pp 226-265.

Yamaoka, M., Hiraba, H., Ueda, K. and Fujiwara, T. (2007) Development of a vibrotactile stimulation apparatus for orofacial rehabilitation. Nihondaigaku Shigakubu Kiyou 35 , pp. 13-18. (in Japanese)

Burdette BH, Gale EN. (1988) The effects of treatment on masticatory muscle activity and mandibular posture in myofascial pain-dysfunction patients. J Dent Res 67; 11261130.

Vriama M, Vanharanta H.(1994) Bony vibrotactile stimulation: A new, non-invasive method for examining intradiscal pain. Eur Spine J 3; 233-235.

Desmedt JE, Codaux E. (1975) Vibration induced discharge patterns of single motor unit in the masseter muscle in man. J Physiol 253; 420-442.

Ivarsen S., Kupfermann F., Kandel ER. (2000a) 50, Emotional States and Feelings. In: Kandel ER., Schwartz JH., Jessell TM., editors, Principles of neuronal science, $4^{\text {th }}$ ed, New York: McGraw-Hill. pp 982-997.

Sakatani K, Yamashita D, Yamanaka T (2006) Changes of cerebral blood oxygenation and optical path length during activation and deactivation in the prefrontal cortex measured by time-resolved near infrared spectroscopy. Life Sciences 78; 2734-2741.

Sakatani K, Lichty W, Xie Y (1999) Effects of aging on language-activated cerebral blood oxygenation changes of the left prefrontal cortex. Near infrared spectroscopy study. J Stroke Cerebrovascular Dis. 8; 398-403.

Hoshi Y, Kobayashi N, Tamura M. (2001) Interpretation of near-infrared spectroscopy signals: A study with a newly developed perfused rat brain model. J Appl Physiol. 90; 1657-1662.

Ivarsen S., Ivarsen L., Saper CB. (2000b) 49, The Autonomic Nervous System and the Hypothalamus. In: Kandel ER., Schwartz JH., Jessell TM., editors, Principles of neuronal science, $4^{\text {th }}$ ed, New York: McGraw-Hill. pp 960-981.

Gardner EP, Martin JH. (2000c) 21, Coding of sensory information. In: Kandel ER., Schwartz JH., Jessell TM., editors, Principles of neuronal science, $4^{\text {th }}$ ed, New York: McGrawHill. pp 411-429.

Chiang CY, Hu W and Sessle BJ (1994) Parabrachial area and nucleus raphe magnusinduced modulation of nociceptive and non-nociceptive trigeminal subnucleus caudalis neurons activated by cutaneous or deep inputs. J. Neurophysiol. 71, 2430-2445.

Petrides M (1994) Frontal lobes and working memory: evidence from investigations of the effects of cortical excisions in nonhuman primates. In: Handbook of Neuropsychology, Vol. 9, F. Boller and J. Grafman (eds.), Elsevier Science B.V., Amsterdam, pp. 50-82.

Yamamoto T, Takemura M, Inui T, Torii K, Maeda N, Ohmoto M, Matumoto I, Abe K. (2009) Functional organization of the rodent parabrachial nucleus. Ann N Y Acad Sci. 1170; 378-382. 
Scott TR and Small DM (2009) The role of the parabrachial nucleus in taste processing and feeding. Ann N.Y. Acad Sci. 1170, 372-377. 


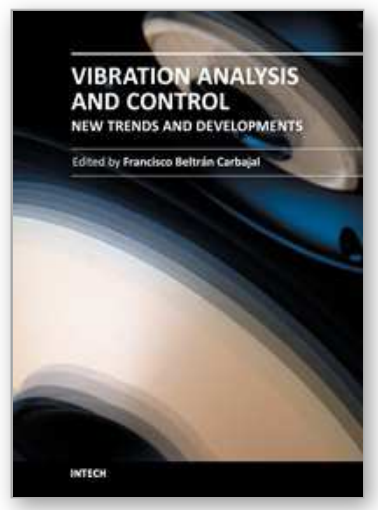

\author{
Vibration Analysis and Control - New Trends and Developments \\ Edited by Dr. Francisco Beltran-Carbajal
}

ISBN 978-953-307-433-7

Hard cover, 352 pages

Publisher InTech

Published online 06, September, 2011

Published in print edition September, 2011

This book focuses on the important and diverse field of vibration analysis and control. It is written by experts from the international scientific community and covers a wide range of research topics related to design methodologies of passive, semi-active and active vibration control schemes, vehicle suspension systems, vibration control devices, fault detection, finite element analysis and other recent applications and studies of this fascinating field of vibration analysis and control. The book is addressed to researchers and practitioners of this field, as well as undergraduate and postgraduate students and other experts and newcomers seeking more information about the state of the art, challenging open problems, innovative solution proposals and new trends and developments in this area.

\title{
How to reference
}

In order to correctly reference this scholarly work, feel free to copy and paste the following:

Hisao Hiraba, Takako Sato, Satoshi Nishimura, Masaru Yamaoka, Motoharu Inoue, Mitsuyasu Sato, Takatoshi lida, Satoko Wada, Tadao Fujiwara and Koichiro Ueda (2011). Changes in Brain Blood Flow on Frontal Cortex Depending on Facial Vibrotactile Stimuli, Vibration Analysis and Control - New Trends and Developments, Dr. Francisco Beltran-Carbajal (Ed.), ISBN: 978-953-307-433-7, InTech, Available from:

http://www.intechopen.com/books/vibration-analysis-and-control-new-trends-and-developments/changes-inbrain-blood-flow-on-frontal-cortex-depending-on-facial-vibrotactile-stimuli

\section{INTECH}

open science | open minds

\section{InTech Europe}

University Campus STeP Ri

Slavka Krautzeka 83/A

51000 Rijeka, Croatia

Phone: +385 (51) 770447

Fax: +385 (51) 686166

www.intechopen.com

\section{InTech China}

Unit 405, Office Block, Hotel Equatorial Shanghai

No.65, Yan An Road (West), Shanghai, 200040, China

中国上海市延安西路65号上海国际贵都大饭店办公楼 405 单元

Phone: +86-21-62489820

Fax: $+86-21-62489821$ 
(C) 2011 The Author(s). Licensee IntechOpen. This chapter is distributed under the terms of the Creative Commons Attribution-NonCommercialShareAlike-3.0 License, which permits use, distribution and reproduction for non-commercial purposes, provided the original is properly cited and derivative works building on this content are distributed under the same license. 